\title{
A Nonhuman Primate PET Study: Measurement of Brain PDE4 Occupancy by Roflumilast Using (R)- $\left[{ }^{11} \mathrm{C}\right]$ Rolipram
}

\author{
Akihiro Takano $\odot,{ }^{1}$ Tolga Uz, ${ }^{2}$ Jesus Garcia-Segovia, ${ }^{3,4}$ Max Tsai, ${ }^{2,5}$ Gezim Lahu, ${ }^{2}$ \\ Nahid Amini, ${ }^{1}$ Ryuji Nakao, ${ }^{1}$ Zhisheng Jia, ${ }^{1}$ Christer Halldin ${ }^{1}$ \\ ${ }^{1}$ Department of Clinical Neuroscience, Center for Psychiatric Research, Karolinska Institutet, Stockholm, Sweden \\ ${ }^{2}$ Takeda Development Center Americas, Inc., Deerfield, IL, 60015, USA \\ ${ }^{3}$ Takeda Development Center, London, UK \\ ${ }^{4}$ Orchard Therapeuitcs, Birchin Lane, London, UK \\ ${ }^{5}$ Eli Lilly and Company, Indianapolis, IN, USA
}

\begin{abstract}
Purpose: Phosphodiesterase 4 (PDE4) inhibition in the brain has been reported to improve cognitive function in animal models. Therefore, PDE4 inhibitors are one of key targets potential for drug development. Investigation of brain PDE4 occupancy would help to understand the effects of PDE4 inhibition to cognitive functions. Roflumilast is a selective phosphodiesterase type 4 (PDE4) inhibitor used clinically for severe chronic obstructive pulmonary disease, but the effects to the brain have not been well investigated. In this study, we aimed to investigate whether roflumilast entered the brain and occupied PDE4 in nonhuman primates.

Procedures: Positron emission tomography (PET) measurements with (R)- $\left[{ }^{11} \mathrm{C}\right]$ rolipram were performed at baseline and after intravenous (i.v.) administration of roflumilast (3.6 to $200 \mu \mathrm{g} / \mathrm{kg}$ ) in three female rhesus monkeys. Arterial blood samples were taken to obtain the input function. Protein binding was measured to obtain the free fraction ( $\mathrm{fp}$ ) of the radioligand. Total distribution volume $\left(V_{T}\right)$ and $V_{T} /$ fp were calculated as outcome measures from two tissue compartment model. Lassen plot approach was taken to estimate the target occupancy.

Results: The brain uptake of $(\mathrm{R})-\left[{ }^{11} \mathrm{C}\right]$ rolipram decreased after roflumilast administration. PDE 4 occupancy by roflumilast showed dose- and plasma concentration-dependent increase, although PDE4 occupancy did not reach $50 \%$ even after the administration of up to $200 \mu \mathrm{g} /$ $\mathrm{kg}$ of roflumilast, regardless of outcome measures, $V_{\mathrm{T}}$ or $V_{\mathrm{T}} / \mathrm{fp}$.

Conclusions: This PET study showed that the brain PDE4 binding was blocked to a certain extent after i.v. administration of clinical relevant doses of roflumilast in nonhuman primates. Further clinical PET evaluation is needed to understand the relationship between PDE4 inhibition and potential improvement of cognitive function in human subjects.
\end{abstract}

Key words: PDE4, Roflumilast, PET, Primate

Electronic supplementary material The online version of this article (https:// doi.org/10.1007/s11307-018-1168-0) contains supplementary material, which is available to authorized users.

Correspondence to: Akihiro Takano; e-mail: akihiro.takano@ki.se

\section{Introduction}

The phosphodiesterase enzyme family plays a vital role for degrading cyclic nucleotides (cyclic adenosine monophosphate (cAMP) and cGMP) in the signal transduction pathway in all 
cells. Phosphodiesterase 4 (PDE4) is mainly distributed in the immune cells, brain, and cardiovascular tissues [1,2]. Roflumilast is the first PDE4 inhibitor to be approved for the treatment of severe chronic obstructive pulmonary disease [3]. Apremilast, another registered PDE4 inhibitor, has been introduced for the treatment of skin diseases such as psoriatic arthritis [4, 5].

In regard to the central nervous system (CNS), the inhibition of PDE4 has been reported to have effects in various in vivo models of behavior and inflammation [6]. By preventing the cAMP hydrolysis, PDE4 inhibitors are considered to enhance intracellular signal transduction and increase the phosphorylation of cAMP response elementbinding protein (CREB), which enhances the transcription of proteins involved in synaptic plasticity and memory formation [7]. Rolipram has been reported to improve cognitive function in animal models of cognitive impairment in neuropsychiatric and neurodegenerative diseases such as schizophrenia and Alzheimer's disease [8-13].

However, the degree of PDE4 inhibition which could be necessary to translate into improvements of cognitive domains has not been fully evaluated in vivo. Therefore, it would be helpful for further understanding and development of PDE4 inhibitors to measure brain target occupancy using clinically available PDE4 inhibitors.

In this positron emission tomography (PET) study, we aimed to investigate in nonhuman primates whether roflumilast entered the brain and demonstrated specific target occupancy of PDE4 using (R)-[ ${ }^{11}$ C]rolipram, a PET radioligand for PDE4 [14, 15].

\section{Materials and Methods}

\section{Preparation of $(R)-\left[{ }^{11} C\right]$ Rolipram}

(R)- $\left[{ }^{11} \mathrm{C}\right]$ rolipram was synthesized as previously reported in detail [16]. Shortly, (R)-[ $\left.{ }^{11} \mathrm{C}\right]$ rolipram was synthesized by ${ }^{11} \mathrm{C}$-methylation of (R)-desmethyl-rolipram in acetone by using $\left[{ }^{11} \mathrm{C}\right]$ methyl triflate. Purification was performed on a reversed phase HPLC. Radiochemical purity of labeled ligand was more than $99 \%$.

\section{PET Study}

Three female rhesus monkeys (mean weight $\pm \mathrm{SD}, 9.5 \pm$ $2.4 \mathrm{~kg}$, age $8.6 \pm 0.1$ years old) were examined. The monkeys are owned by the Centre for Psychiatry Research, Department of Clinical Neuroscience, Karolinska Institutet, and housed in the Astrid Fagraeus Laboratory of the Swedish Institute for Infectious Disease Control. The study was approved by the Animal Research Ethics Committee of the Swedish Animal Welfare Agency (Northern Stockholm Region) (N 452/11) and was performed according to the relevant guidelines of the Karolinska Institutet ("Guidelines for Planning, Conducting and Documenting Experimental Research" (Dnr 4820/06-600).
To anesthetize the monkeys during the PET experiments, ketamine hydrochloride (approximately $10 \mathrm{mg} / \mathrm{kg}$ ) was initially administered intramascularily, and, after endotracheal intubation, a mixture of sevoflurane (2-8\%), $\mathrm{O}_{2}$, and medical air was administered to maintain the anesthesia. The head was immobilized to the PET bed with a fixation device [17].

The HRRT scanner (Siemens) was used to acquire PET data. A 6-min transmission scan using a single Cs-137 source was performed immediately prior to injection of the (R)[11C]rolipram. PET emission data were acquired for $93 \mathrm{~min}$ as list mode just after injection of radioligand (151-178 MBq; specific radioactivity: more than $188 \mathrm{GBq} / \mu \mathrm{mol}$ and injected mass: less than $0.26 \mu \mathrm{g})$. For the reconstruction of PET images, the ordinary Poisson three-dimensional ordered-subset expectation maximization (OSEM) algorithm was used with 10 iterations and 16 subsets, including modeling of the point spread function, after correction for attenuation, random, and scatter. The resolution of the reconstructed PET images was $1.5 \mathrm{~mm}$ in full width at half maximum [18]. The frame duration of the PET images was as follows: $10 \mathrm{~s} \times 9,15 \mathrm{~s} \times 2,20 \mathrm{~s} \times 3$, $30 \mathrm{~s} \times 4,60 \mathrm{~s} \times 4,180 \mathrm{~s} \times 4$, and $360 \mathrm{~s} \times 12$.

Two brain PET measurements were performed, in one day, under the untreated baseline condition, and after intravenous administration of roflumilast, a selective PDE4 inhibitor. Doses of roflumilast were 3.6, 12, 24, 100, and $200 \mu \mathrm{g} / \mathrm{kg}$. Twelve micrograms per kilogram and $100 \mu \mathrm{g} / \mathrm{kg}$ of roflumilast were administered to monkey $1,3.6$ and $200 \mu \mathrm{g} / \mathrm{kg}$ were administered to monkey 2 , and $24 \mu \mathrm{g} / \mathrm{kg}$ was administered to monkey 3 . Roflumilast was administered $3 \mathrm{~h}$ before the radioligand injection. The duration of the administration was 10 min with syringe pump at the speed of $1 \mathrm{ml} / \mathrm{kg}$. The time between two PET measurements was approximately $4.5 \mathrm{~h}$. The time between two PET measurements with different doses was more than 5 weeks for monkey 1 and monkey 2 .

Arterial blood was collected continuously for 3 min using an automated blood-sampling system (ABSS; Allog AB) at a speed of $3 \mathrm{ml} / \mathrm{min}$ from arterial catheter in an artery of the lower limb. One arterial blood sample $(2 \mathrm{ml})$ was taken at 5 min before the radioligand injection to measure the protein binding of the radioligand.

To measure the radioactivity in blood and plasma and the fraction of the metabolite, arterial blood samples (1-2 ml) were drawn at 4, 15, 30, 45, 60, and $90 \mathrm{~min}$ after the injection of the radioligand.

Venous blood samples were taken at $-1,10,20,40,65$, and $91 \mathrm{~min}$ after the radioligand injection to obtain the plasma concentration of roflumilast and a metabolite, Noxidate roflumilast.

\section{Metabolite Analysis of $(R)-\left[{ }^{11} C\right]$ Rolipram}

The amount of unchanged (R)- $\left[{ }^{11} \mathrm{C}\right]$ rolipram and its radioactive metabolites in monkey plasma was measured using a 
reversed-phase radio-HPLC method. After centrifugation of blood at $2000 \times g$ for $2 \mathrm{~min}$, the plasma was mixed with acetonitrile (1:1.4). Then, the mixture was centrifuged at $2000 \times \mathrm{g}$ for $4 \mathrm{~min}$, and the supernatant of the mixture was injected into a HPLC system coupled to an online radioactivity detector. The used radio-HPLC system consisted of an interface module (D-7000; Hitachi: Tokyo, Japan), a L-7100 pump (Hitachi), an injector (model 7125, $5.0 \mathrm{ml}$ loop; Rheodyne: Cotati, USA), and an ultraviolet absorption detector (L-7400, $254 \mathrm{~nm}$; Hitachi) in series with a 150TR Packard radioactivity detector (housed in a shield of $50 \mathrm{~mm}$ thick lead and equipped with a 550-1 flow cell). Chromatographic separation was made on a XBridge $\mathrm{C} 18$ column, $(50 \mathrm{~mm} \times 10 \mathrm{~mm}$ I.D., $2.5 \mu \mathrm{m}+10 \mathrm{~mm} \times 10 \mathrm{~mm}$ I.D., $5 \mu \mathrm{m}$; Waters: New England, USA) using gradient elution. Acetonitrile (A) and $20 \mathrm{mM}$ ammonium phosphate (pH 7) (B) were used as the mobile phase at $6.0 \mathrm{ml} / \mathrm{min}$, according to the following program: $0-3.5 \mathrm{~min},(\mathrm{~A} / \mathrm{B})$ $25: 75 \rightarrow 55: 45 v / v ; 3.5-4.0 \mathrm{~min},(\mathrm{~A} / \mathrm{B}) \quad 55: 45 v / v ; 4.0$ $4.1 \mathrm{~min},(\mathrm{~A} / \mathrm{B}) 55: 45 \rightarrow 25: 75 v / v ; 4.1-5.0 \mathrm{~min}$, and (A/B) 25:75 v/v. Peaks for radioactive compounds that were eluted from the column were integrated, and their areas were expressed as a percentage of the sum of the areas detected radioactive compounds (decay-corrected to the time of injection on the HPLC).

\section{Measurement of Free Fraction of (R)- ${ }^{11}$ C]Rolipram}

The free fraction, fp, of (R)-[ $\left.{ }^{11} \mathrm{C}\right]$ rolipram in monkey plasma was estimated using an ultrafiltration method. Initially, plasma $(500 \mu \mathrm{l})$ or phosphate buffered saline solution $(500 \mu \mathrm{l})$ as a control were mixed with (R)[11C]rolipram $(50 \mu 1, \sim 1 \mathrm{MBq})$ and then incubated at room temperature for $10 \mathrm{~min}$. After the incubation, $200 \mu 1$ portions of the incubation mixtures were pipetted into ultrafiltration tubes (Centrifree YM-30, Millipore). Then, they were centrifuged at $1500 \times \mathrm{g}$ for $15 \mathrm{~min}$. Radioactivity in equal aliquots $(20 \mu 1)$ of the ultrafiltrate (Cfree) and of the plasma (Ctotal) was counted using a $\mathrm{NaI}$ well counter. Each determination was performed in triplicate. The free fraction was then calculated as $\mathrm{fp}=$ Cfree / Ctotal, and after the correction for the membrane binding measured with the control samples, the final results were obtained.tpb

\section{MRI Measurements}

An MRI system GE 1.5 T Sigma unit (Milwaukee, WI, USA) was used to obtain T1-weighted MR images. A 3-D SPGR protocol with the following settings was used as the T1 sequence: repetition time (TR) $21 \mathrm{~ms}$, flip angle $35^{\circ}$, FOV 12.8 , and matrix $256 \times 256 \times 128,128 \times 1.0 \mathrm{~mm}$ slices.

\section{PET Data Analysis}

Regions of interest (ROIs) were delineated manually on the putamen, caudate, hippocampus, amygdale, thalamus, pons, frontal cortex, temporal cortex, anterior cingulate cortex, occipital cortex, parietal cortex, and cerebellum on the coregistered MRI/PET images. Regional uptake was expressed as percentage of standard uptake value (\%SUV), which equals uptake $(\mathrm{MBq} / \mathrm{ml}) /$ injected radioactivity $(\mathrm{MBq}) \times$ body weight $(\mathrm{g}) \times 100$.

The total distribution volume $\left(V_{\mathrm{T}}\right)$ and $V_{\mathrm{T}} / \mathrm{fp}$ of $(\mathrm{R})-$ $\left[{ }^{11} \mathrm{C}\right]$ rolipram was calculated with two-tissue compartment models using metabolite-corrected plasma input [19, 20]. Because there were no appropriate regions for the reference region, Lassen plot approach was applied for the current data to estimate the target occupancy and the distribution volume $\left(V_{\mathrm{ND}}\right)$ of free and nonspecifically bound radioligand [21, 22].

The relationship between the target occupancy and the plasma concentration of the drug (roflumilast, N-oxide roflumilast, and the sum of roflumilast and $\mathrm{N}$-oxide roflumilast) was examined using the following hyperbolic function.

Occupancy $(\%)=\mathrm{Occ}_{\max } \times \mathrm{Cp} /(\mathrm{Kd}+\mathrm{Cp})$

where $\mathrm{Cp}$ is the concentration of the drug, and $\mathrm{Kd}$ is the plasma concentration required to produce $50 \%$ of the maximal target occupancy. The area under the curve (AUC) during the 90 min PET measurements divided by the time length of 90 min was used as the plasma level of the drug at the PET measurements.

Occ $_{\max }$ was evaluated in two ways. One was a priori fixed to $100 \%$ while the other was estimated by fitting data.

\section{Results}

Summed PET images at baseline and after administration of $200 \mu \mathrm{g} / \mathrm{kg}$ of roflumilast are shown in Fig. 1. There was high accumulation of the radioligand in the thalamus and striatum (caudate and putamen) and moderate accumulation in the cortex at baseline. After administration of roflumilast, accumulation was decreased in all the brain regions.

Time activity curves of the brain regions at baseline and after administration of $200 \mu \mathrm{g} / \mathrm{kg}$ of roflumilast are shown in Fig. 2. Compared with the baseline, initial brain uptake of (R)- $\left[{ }^{11} \mathrm{C}\right]$ rolipram was a little higher after administration of roflumilast, but the washout from the brain was faster. For the cerebellum, the peak value was $534 \% \mathrm{SUV}$ and the time to decrease to half was approximately $16.5 \mathrm{~min}$ at the baseline while the peak value was $585 \%$ SUV and the time to decrease to half was approximately $8 \mathrm{~min}$ after roflumilast administration.

The parent fraction of (R)- $\left[{ }^{11} \mathrm{C}\right]$ rolipram in the plasma decreased to $32.3 \pm 6.4 \%$ at $15 \mathrm{~min}$ and $14.9 \pm 0.1 \%$ at $90 \mathrm{~min}$, and the metabolite rate did not change significantly 


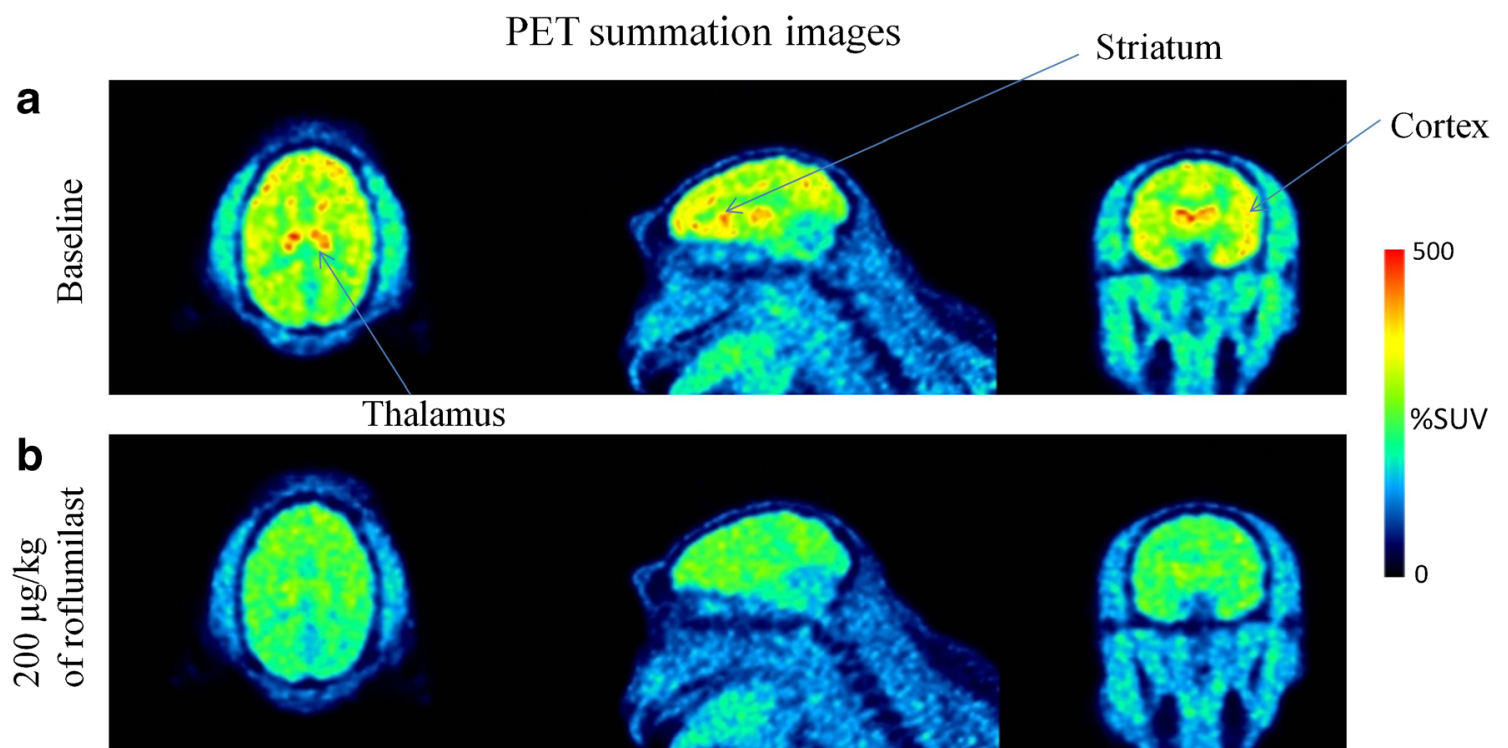

Fig. 1. PET images of $(\mathrm{R})-\left[{ }^{11} \mathrm{C}\right]$ rolipram summed from 15 to $90 \mathrm{~min}$. a Baseline. $\mathbf{b}$ After administration of $200 \mu \mathrm{g} / \mathrm{kg}$ of roflumilast.

after roflumilast treatment. There were no radioactive metabolites that were more lipophilic than (R)$\left[{ }^{11} \mathrm{C}\right]$ rolipram. Free fraction of the radioligand was $39.5 \pm$ $6.0 \%$ at baseline and $44.7 \pm 3.6 \%$ after roflumilast administration. There was no correlation between the change of the free fraction and roflumilast concentration.

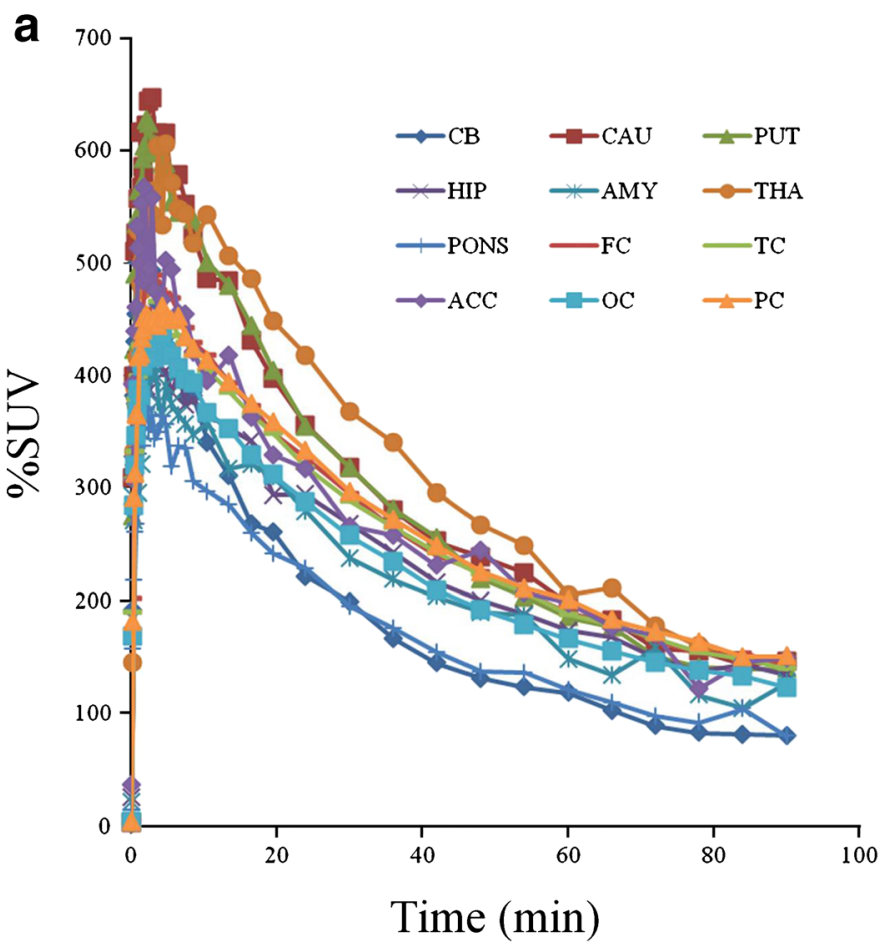

The calculated $V_{\mathrm{T}}$ and $V_{\mathrm{T}} / \mathrm{fp}$ and the percent change of one monkey for whom one baseline PET and post-treatment PET with $200 \mu \mathrm{g} / \mathrm{kg}$ of roflumilast are shown in Table 1. All the brain regions showed the decrease of the $V_{\mathrm{T}}$ and $V_{\mathrm{T}} / \mathrm{fp}$. There was no brain region which can be used as reference region for simplified quantification.

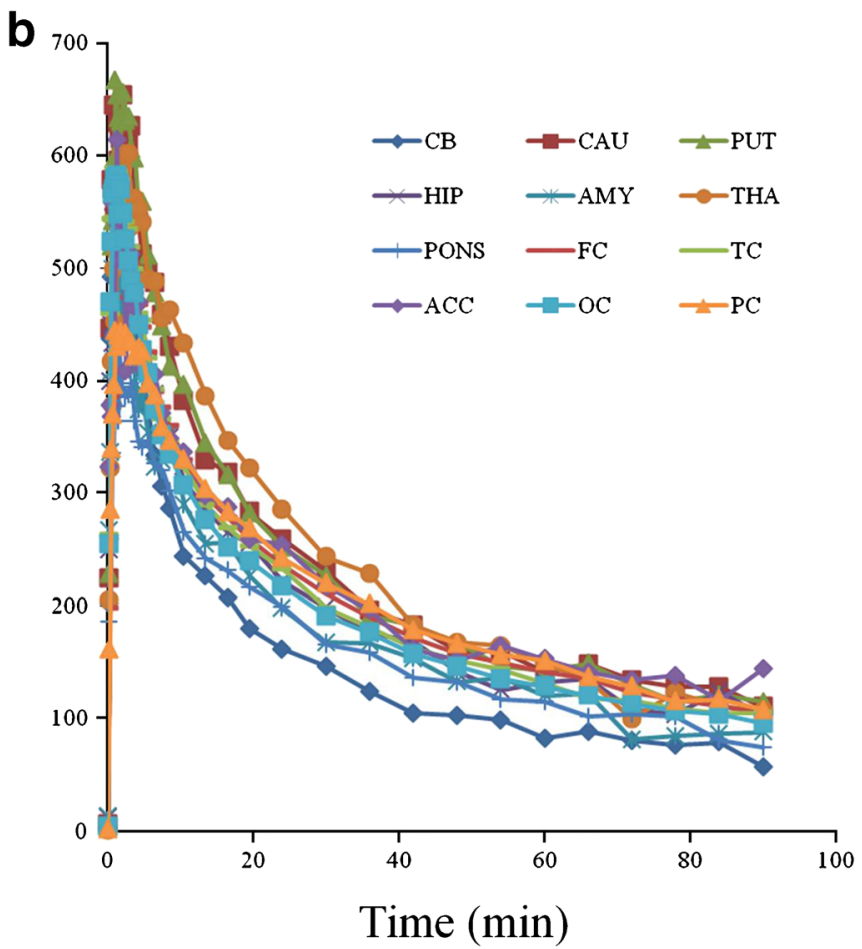

Fig. 2. Brain regional time activity curves of $(\mathrm{R})-\left[{ }^{11} \mathrm{C}\right]$ rolipram at $\mathbf{a}$ baseline and $\mathbf{b}$ after $200 \mu \mathrm{g}$ of roflumilast. $\mathrm{CB}$ cerebellum, CAU caudate, PUT putamen, HIP hippocampus, AMY amygdala, THA; thalamus, FC frontal cortex, TC temporal cortex, ACC anterior cingulated cortex, OC occipital cortex, PC parietal cortex. Percentage of standard uptake value (\%SUV) equals uptake $(\mathrm{MBq} / \mathrm{ml}) /$ injected radioactivity $(\mathrm{MBq}) \times$ body weight $(\mathrm{g}) \times 100$. 
Table 1.. $V_{\mathrm{T}}$ and $V_{\mathrm{T}} /$ fp calculated by two tissue compartment model and the percent change in a monkey at the baseline and after $200 \mu \mathrm{g} / \mathrm{kg}$ of roflumilast i.v. administration

\begin{tabular}{|c|c|c|c|c|c|c|}
\hline & \multicolumn{2}{|l|}{$V_{\mathrm{T}}$} & \multirow[t]{2}{*}{$\%$ change } & \multicolumn{2}{|l|}{$V_{\mathrm{T}} / \mathrm{fp}$} & \multirow[t]{2}{*}{$\%$ change } \\
\hline & Baseline & Roflumilast & & Baseline & Roflumilast & \\
\hline $\mathrm{CB}$ & 3.0 & 2.3 & 23.8 & 7.6 & 5.6 & 26.5 \\
\hline CAU & 5.4 & 3.9 & 28.3 & 13.7 & 9.5 & 30.8 \\
\hline PUT & 5.0 & 3.8 & 24.3 & 12.7 & 9.3 & 26.9 \\
\hline HIP & 4.5 & 3.4 & 25.2 & 11.5 & 8.3 & 27.7 \\
\hline AMY & 4.1 & 2.8 & 31.0 & 10.4 & 6.9 & 33.4 \\
\hline THA & 5.5 & 3.7 & 32.4 & 13.9 & 9.1 & 34.7 \\
\hline PONS & 3.0 & 2.7 & 11.5 & 7.7 & 6.6 & 14.5 \\
\hline $\mathrm{FC}$ & 4.9 & 3.4 & 30.1 & 12.4 & 8.4 & 32.5 \\
\hline $\mathrm{TC}$ & 4.9 & 3.3 & 32.2 & 12.3 & 8.1 & 34.5 \\
\hline ACC & 4.9 & 3.8 & 23.7 & 12.6 & 9.3 & 26.4 \\
\hline $\mathrm{OC}$ & 4.3 & 3.2 & 26.2 & 10.9 & 7.8 & 28.8 \\
\hline $\mathrm{PC}$ & 5.0 & 3.5 & 30.4 & 12.7 & 8.5 & 32.8 \\
\hline
\end{tabular}

Lassen plots of PET data after $200 \mu \mathrm{g} / \mathrm{kg}$ of roflumilast administration are shown in Fig. 3. The occupancy at $200 \mu \mathrm{g} / \mathrm{kg}$ of roflumilast was $43.5 \%$ calculated using $V_{\mathrm{T}}$ and $45.5 \%$ calculated using $V_{\mathrm{T}} / \mathrm{fp}$. Estimated PDE4 occupancy and the dose and mean plasma concentration of roflumilast at PET measurements are shown in Table 2. Regardless of the outcome measures of $V_{\mathrm{T}}$ and $V_{\mathrm{T}} / \mathrm{fp}$, PDE4 occupancy was lower than $50 \%$ when up to $200 \mu \mathrm{g} / \mathrm{kg}$ of rofulmilast was administered. Plasma concentrations during drug treatment PET measurements for each monkey are shown in Suppl. Fig. 1 (see ESM). The plasma concentrations of roflumilast and $\mathrm{N}$-oxide roflumilast were fairly constant during PET measurements.

The relationship between PDE4 occupancy and the plasma concentration of the drug at the PET measurement is shown in Fig. 4 and Suppl. Fig. 2. The curve fitting was better when the target occupancy was calculated using $V_{\mathrm{T}}$. Curve fitting was better when maximal occupancy was

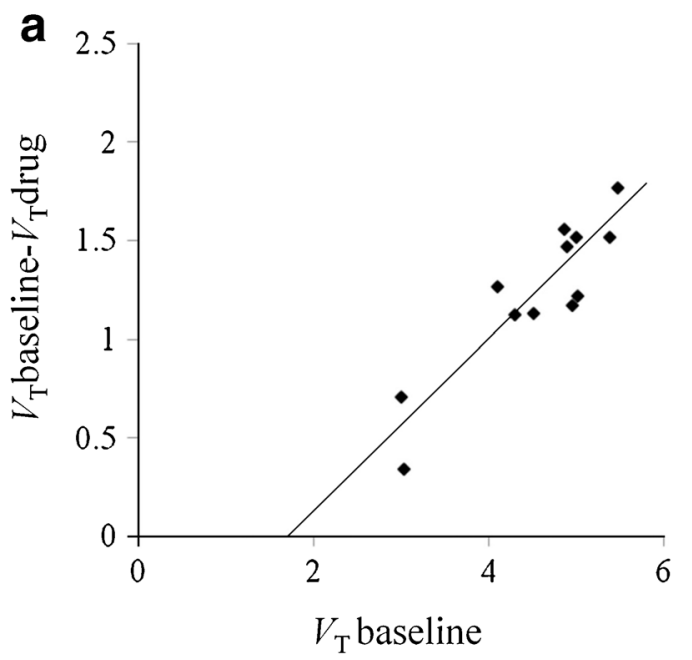

estimated by the model than when the occupancy was fixed to $100 \%$. The estimated $K_{\mathrm{d}}$ values and estimated maximal occupancy are summarized in Table 3 . The estimated maximal occupancy was 53.1 to $57.4 \%$.

\section{Discussion}

This PET study showed that roflumilast, a PDE4 inhibitor used for the treatment of COPD, enters the brain and binds to PDE4 in a dose-dependent manner in nonhuman primate brain. However, PDE4 occupancy in the brain was lower than $50 \%$ even when up to $200 \mu \mathrm{g} / \mathrm{kg}$ of rofulmilast was administered.

Roflumilast is the first PDE4 inhibitor to be licensed for the treatment of COPD and was approved in Europe in 2010 and in the USA in 2011 as an oral add-on treatment of COPD. Roflumilast is metabolized principally via the liver into N-oxide roflumilast, which is pharmacologically active with a lower potency but longer half-life than the parent compound [23, 24]. Roflumiast was reported to have no PDE4 subtype selectivity apart from PDE4C while N-oxide rofulmilast has no selectivity for PDE4 subtypes [25]. Therefore, both roflumilast and N-oxide roflumilat have potentials to contribute to PDE4 occupancy.

In this study, roflumilast was administered $3 \mathrm{~h}$ before the PET radioligand administration in order to imitate the relationship between roflumilast and $\mathrm{N}$-oxide roflumilast in clinical settings based on internal data (data were not shown).

$\mathrm{N}$-oxide roflumilast was detected under all the drug treatment conditions in this study, and the ratio of the plasma concentration between roflumilast and $\mathrm{N}$-oxide roflumilast was rather constant during PET measurements under all the drug treatment conditions (Suppl. Table 1). Time-dependent different contributions of roflumilast and $\mathrm{N}$-oxide roflumilast to the target binding could not be evaluated due to the constant ratio between them.

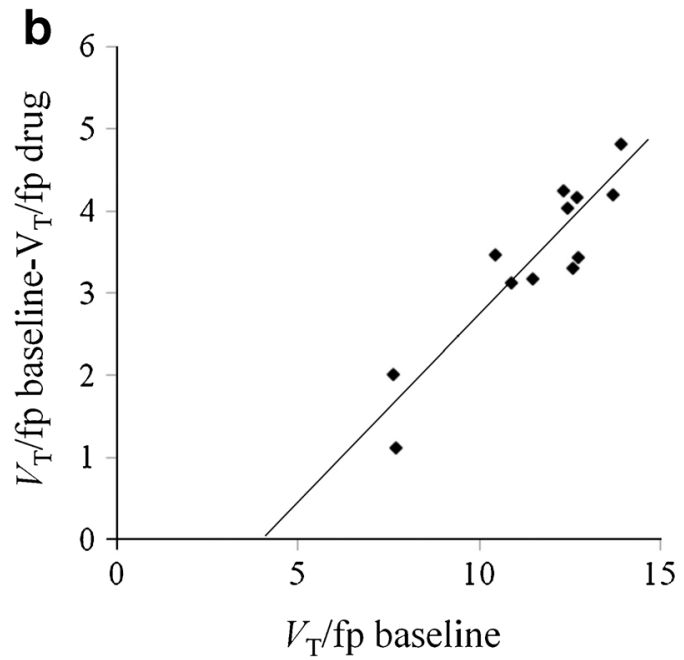

Fig. 3. The occupancy estimation using the Lassen plot. The slope corresponds to the occupancy and the intersection with $x$ axis corresponds to $V_{\mathrm{ND}}$. $\mathbf{a} V_{\mathrm{T}}$ is used as the outcome measures. The equation of the linear fitting: $Y=0.4353 X-0.7409$. $\mathbf{b} V_{\mathrm{T}} / \mathrm{fp}$ is used as the outcome measure. The equation of the linear fitting: $Y=0.4548 X-1.8163$. 
Table 2.. PDE4 occupancy by roflumilast calculated with two different outcome measures $\left(V_{\mathrm{T}}\right.$ and $\left.V_{\mathrm{T}} / \mathrm{fp}\right)$

\begin{tabular}{lllll}
\hline $\begin{array}{l}\text { Intravenous administration } \\
\text { dose of roflumilast }(\mu \mathrm{g} / \mathrm{kg})\end{array}$ & $\begin{array}{l}\text { Mean concentration of } \\
\text { roflumilast }(\mathrm{ng} / \mathrm{ml})\end{array}$ & $\begin{array}{l}\text { mean concentration of } \\
\text { N-oxide roflumilast }(\mathrm{ng} / \mathrm{ml})\end{array}$ & $\begin{array}{l}\text { Occupancy (\%) } \\
\text { using } V_{\mathrm{T}}\end{array}$ \\
\hline 200 & 17.1 & 57.9 & 43.5 & $\begin{array}{l}\text { Occupancy (\%) } \\
\text { using } V_{\mathrm{T}} / \mathrm{fp}\end{array}$ \\
100 & 8.1 & 24.0 & 34.7 & 45.5 \\
24 & 1.3 & 4.7 & 18.5 & 48.1 \\
12 & 1.0 & 1.9 & -0.6 & 5.1 \\
3.6 & 0.5 & 0.9 & 4.5 & 2.5 \\
\hline
\end{tabular}

In this study, the doses of roflumilast were selected in order to imitate the plasma concentration in the clinical setting. The plasma concentration of roflumilast and $\mathrm{N}$-oxide roflumilast after oral administration of $500 \mu \mathrm{g}$ of roflumilast, the recommended clinical dose, in human subjects has been reported to be approximately 5 and $9 \mathrm{ng} / \mathrm{ml}$ at peak concentration, respectively [23]. As shown in Table 2, the doses up to $200 \mu \mathrm{g} / \mathrm{kg}$ of rofulmilast covered the range of the plasma concentration in the clinical settings. Although we have to take into consideration the species difference between the human and NHPs, the estimated PDE4 occupancy of $500 \mu \mathrm{g}$ of roflumilast would be up to approximately $30-40 \%$ if we apply the human plasma data to the present NHP results of the relationship between the occupancy and the plasma concentration.

The relationship between the target occupancy and plasma concentration suggested that the plotted data fitted better when the maximal occupancy were not fixed as shown in Fig. 4. On the other hand, $\left[{ }^{3} \mathrm{H}\right]$ rolipram binding was reported to be fully blocked by roflumilast [26]. (R)$\left[{ }^{11} \mathrm{C}\right]$ rolipram rat PET study that the brain uptake of (R)$\left[{ }^{11} \mathrm{C}\right]$ rolipram was almost completely blocked by cold rolipram [27]. Considering non-PDE4 subtype selectivity of both rolipram and roflumilast [24, 28], full blocking of (R)- $\left[{ }^{11} \mathrm{C}\right]$ rolipram would be expected by roflumilast

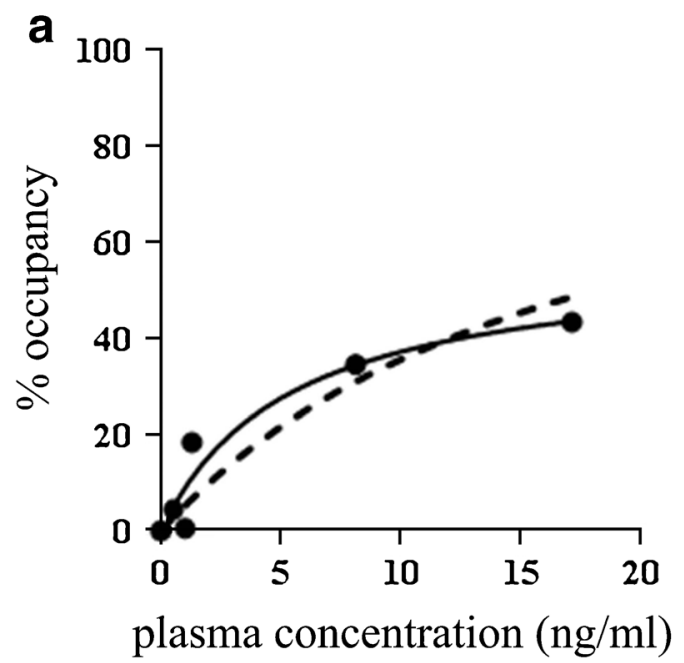

administration. Higher doses of roflumilast than what we tested in this study would be needed to investigate in order to confirm whether in vivo maximal target occupancy with (R)- $\left[{ }^{11} \mathrm{C}\right]$ rolipram can reach $100 \%$ or not.

As outcome measures, $V_{\mathrm{T}}$ and $V_{\mathrm{T}} / \mathrm{fp}$ of $(\mathrm{R})-\left[{ }^{11} \mathrm{C}\right]$ rolipram were calculated in this study because $V_{\mathrm{T}}$ and $V_{\mathrm{T}} / \mathrm{fp}$ of (R)$\left[{ }^{11} \mathrm{C}\right]$ rolipram were reported to have comparable reproducibility [19], and there was possible change of fp after roflumilast administration. The relationship between the roflumilast and the PDE4 occupancy was weaker when $V_{\mathrm{T}} /$ fp was used to calculate the target occupancy than $V_{\mathrm{T}}$ was used as shown in Fig. 4. In theory, as only free (R)$\left[{ }^{11} \mathrm{C}\right]$ rolipram is considered to enter the brain, correction for fp $\left(V_{\mathrm{T}} / \mathrm{fp}\right)$ should more accurately reflect binding than that without correction $\left(V_{\mathrm{T}}\right)$. However, the inclusion of fp in the calculation may introduce additional variability associated with measurement of protein binding. In this study, fp values at the baseline in the same monkeys (monkey 1 and monkey 2) showed rather high variability at different study days (Suppl. Fig. 3). High variability might arrive from technical issues with measurement of protein binding as well as potential physiological conditions in monkeys under anesthesia of induction by ketamine and maintenance by sevoflurane. There was no clear dose-dependent change of fp before and after roflumilast administration although the

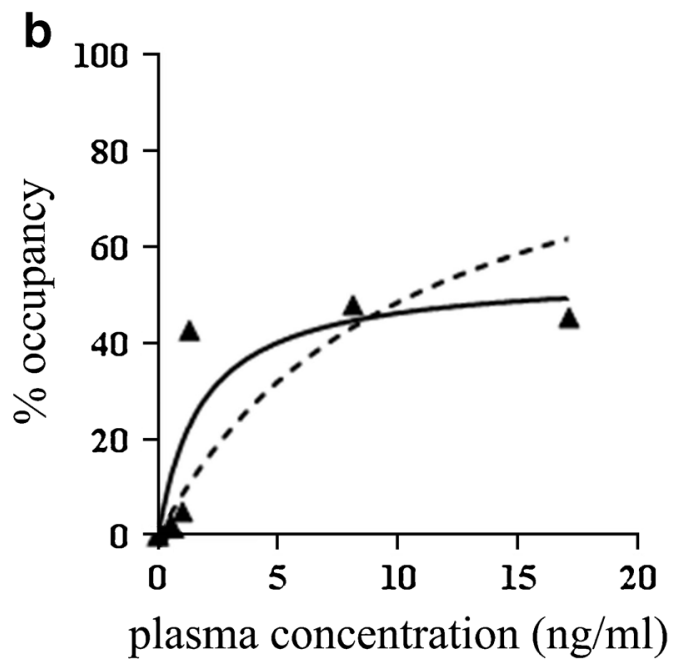

Fig. 4. The relationship between PDE4 occupancy and the plasma concentration of roflumilast. a The relationship based on the target occupancy using $V_{\mathrm{T}}$. $\mathbf{b}$ The relationship based on the target occupancy using $V_{\mathrm{T}} / \mathrm{fp}$. Dotted lines show the hyperbola where the maximal occupancy was fixed to $100 \%$. Solid lines show the hyperbola where the maximal occupancy was estimated by the fitting. $K_{d}$ values and estimated $\mathrm{Occ}_{\max }$ values are shown in Table 3. 
Table 3.. $K_{\mathrm{d}}$ values and estimated $\mathrm{Occu}_{\max }$ of the plotted data

\begin{tabular}{|c|c|c|c|c|}
\hline \multirow[b]{2}{*}{ Drug } & \multicolumn{2}{|l|}{$V_{\mathrm{T}}$} & \multicolumn{2}{|l|}{$V_{\mathrm{T}} / \mathrm{fp}$} \\
\hline & $100 \% \mathrm{Occu}_{\max }$ & Estimated $\mathrm{Occ}_{\max }$ & $100 \% \mathrm{Occu}_{\max }$ & Estimated $\mathrm{Occ}_{\max }$ \\
\hline Roflumilast & $17.9 \mathrm{ng} / \mathrm{ml}\left(R^{2}=0.90\right)$ & $5.4 \mathrm{ng} / \mathrm{ml}\left(R^{2}=0.94\right), 57.4 \%$ & $10.5 \mathrm{ng} / \mathrm{ml}\left(R^{2}=0.53\right)$ & $1.8 \mathrm{ng} / \mathrm{ml}\left(R^{2}=0.74\right), 54.8 \%$ \\
\hline N-oxide roflumilast & $56.8 \mathrm{ng} / \mathrm{ml}\left(R^{2}=0.89\right)$ & $12.6 \mathrm{ng} / \mathrm{ml}\left(R^{2}=0.97\right), 53.1 \%$ & $31.0 \mathrm{ng} / \mathrm{ml}\left(R^{2}=0.54\right)$ & $4.2 \mathrm{ng} / \mathrm{ml}\left(R^{2}=0.85\right), 54.0 \%$ \\
\hline $\begin{array}{l}\text { Sum of roflumilast and } \\
\text { N-oxide roflumilast }\end{array}$ & $74.8 \mathrm{ng} / \mathrm{ml}\left(R^{2}=0.89\right)$ & $17.7 \mathrm{ng} / \mathrm{ml}\left(R^{2}=0.96\right), 54.0 \%$ & $41.7 \mathrm{ng} / \mathrm{ml}\left(R^{2}=0.53\right)$ & $6.0 \mathrm{ng} / \mathrm{ml}\left(R^{2}=0.82\right), 54.1 \%$ \\
\hline
\end{tabular}

Plotted data in Fig. 4 and Suppl. Fig. 2

limited number of the data sets and high variability of fp at the baseline condition might obscure the relation (Suppl. Fig. 3). The target occupancy estimated by $V_{\mathrm{T}} / \mathrm{fp}$ was influenced by fp values directly. Considering high variability of fp values at the baseline condition and no clear trend of $\mathrm{fp}$ changes before and after roflumilast administration, the target occupancy estimated by $V_{\mathrm{T}} / \mathrm{fp}$ would be overestimated or underestimated easily. Therefore, the outcome measures without $\mathrm{fp}$ were considered to be more robust in this study.

Compared with other PDE4 inhibitors whose development was stopped due to side effects of nausea and emesis, side effects are typically mild to moderate with roflumilast [29]. Emesis induced by PDE4 inhibitors was reported to be related to the degree of PDE4 inhibition based on the ex vivo evaluation of $\left[{ }^{3} \mathrm{H}\right]$ rolipram binding in the brain although roflumilast was not included in the study [30]. Although species difference is needed to consider, the present study may suggest that 30-40\% of in vivo brain PDE4 occupancy, which corresponds to clinical dose of roflumilast, might be an acceptable level of PDE4 inhibition not to induce severe nausea and emesis if the in vivo brain target occupancy can be used as an objective parameter. In order to confirm it, direct evaluation between the brain occupancy of PDE4 inhibitors and occurrence of emesis would be necessary in human subjects.

In a recent meta-analysis of roflumilast clinical data [31], 2$5 \%$ of the patients who took roflumiast showed potentially CNSrelated side effects such as insomnia, dizziness, and headache. This may support our results of brain penetration of roflumilast.

There has been no clinical data to show the improvement of cognition by PDE4 inhibitors in clinical settings although several lines of research using animal models suggest that PDE4 inhibition could improve some cognitive domains such as executive functions and memory $[32,33]$. Regarding PDE4 subtypes, PDE4D is considered to be related to cognitive improvement $[34,35]$ while PDE4B is also considered to be involved in the cognitive function [36]. It would be worth investigating in future the relationship among treatment with roflumilast, PDE4 occupancy, and effects on cognitive domains in preclinical and clinical settings.

Rolipram binds nonselectively to all PDE4 subtypes (Bruno et al., 2009). As the subtypes differ with respect to their regulatory behavior and tissue expression patterns, PET radioligands with more selective to the subtypes of PDE4 would help to understand the function of PDE4 subtypes in future.
Each dose of roflumilast was investigated only in one monkey. Investigation of the same dose in multiple monkeys would help to evaluate more detailed $\mathrm{Kd}$ values.

\section{Conclusions}

This PET study showed a certain level of in vivo brain PDE4 occupancy after administration of clinically relevant doses of roflumilast, in nonhuman primates. The results would facilitate investigating the relationship between brain PDE4 occupancy and putative procognitive properties of PDE4 inhibitors in human subjects.

Acknowledgements. The authors thank all the members of the Karolinska PET group for their assistance in the PET experiments, including special thanks to Gudrun Nylen, for excellent technical assistance.

Compliance with Ethical Standards. The study was approved by the Animal Research Ethics Committee of the Swedish Animal Welfare Agency (Northern Stockholm Region) (N 452/11) and was performed according to the relevant guidelines of the Karolinska Institutet ("Guidelines for Planning, Conducting and Documenting Experimental Research” (Dnr 4820/06-600).

\section{Conflict of Interest}

This work was sponsored by Takeda Pharmaceutical Company Limited. TU, JGS, GL, and MT were employees of Takeda Pharmaceutical Company Limited when this study was conducted.

Open Access This article is distributed under the terms of the Creative Commons Attribution 4.0 International License (http:// creativecommons.org/licenses/by/4.0/), which permits unrestricted use, distribution, and reproduction in any medium, provided you give appropriate credit to the original author(s) and the source, provide a link to the Creative Commons license, and indicate if changes were made.

\section{References}

1. Houslay MD, Sullivan M, Bolger GB (1998) The multienzyme PDE4 cyclic adenosine monophosphate-specific phosphodiesterase family: intracellular targeting, regulation, and selective inhibition by compounds exerting antiinflammatory and antidepressant actions. Adv Pharmacol 44:225-342. https://doi.org/10.1016/S1054-3589(08)60128-3

2. Tenor H, Hatzelmann A, Church MK, Schudt C, Shute JK (1996) Effects of theophylline and rolipram on leukotriene C4 (LTC4) synthesis and chemotaxis of human eosinophils from normal and atopic subjects. Br J Pharmacol 118(7):1727-1735. https://doi.org/ 10.1111/j.1476-5381.1996.tb15598.x

3. Giembycz MA, Field SK (2010) Roflumilast: first phosphodiesterase 4 inhibitor approved for treatment of COPD. Drug Des Devel Ther 4:147-158

4. Harrison C (2013) Trial watch: PDE4 inhibitor leads wave of targetspecific oral psoriasis drugs. Nat Rev Drug Discov 12(5):335. https:// doi.org/10.1038/nrd4017 
5. Schafer PH, Day RM (2013) Novel systemic drugs for psoriasis: mechanism of action for apremilast, a specific inhibitor of PDE4. J Am Acad Dermatol 68(6):1041-1042. https://doi.org/10.1016/ j.jaad.2012.10.064

6. Martinez A, Gil C (2014) cAMP-specific phosphodiesterase inhibitors: promising drugs for inflammatory and neurological diseases. Expert Opin Ther Pat 24(12):1311-1321. https://doi.org/10.1517/ 13543776.2014 .968127

7. Zhong Y, Zhu Y, He T, Li W, Yan H, Miao Y (2016) Rolipram-induced improvement of cognitive function correlates with changes in hippocampal CREB phosphorylation, BDNF and Arc protein levels. Neurosci Lett 610:171-176. https://doi.org/10.1016/j.neulet.2015.09.023

8. Davis JA, Gould TJ (2005) Rolipram attenuates MK-801-induced deficits in latent inhibition. Behav Neurosci 119(2):595-602. https:// doi.org/10.1037/0735-7044.119.2.595

9. Rodefer JS, Saland SK, Eckrich SJ (2012) Selective phosphodiesterase inhibitors improve performance on the ED/ID cognitive task in rats. Neuropharmacology 62(3):1182-1190. https://doi.org/10.1016/ j.neuropharm.2011.08.008

10. Imanishi T, Sawa A, Ichimaru Y, Miyashiro M, Kato S, Yamamoto T, Ueki S (1997) Ameliorating effects of rolipram on experimentally induced impairments of learning and memory in rodents. Eur J Pharmacol 321(3):273-278. https://doi.org/10.1016/S0014-2999(96)00969-7

11. DeMarch Z, Giampa C, Patassini S et al (2008) Beneficial effects of rolipram in the R6/2 mouse model of Huntington's disease. Neurobiol Dis 30(3):375-387. https://doi.org/10.1016/j.nbd.2008.02.010

12. Vitolo OV, Sant'Angelo A, Costanzo V, Battaglia F, Arancio O, Shelanski M (2002) Amyloid beta-peptide inhibition of the PKA/ CREB pathway and long-term potentiation: reversibility by drugs that enhance cAMP signaling. Proc Natl Acad Sci U S A 99(20):1321713221. https://doi.org/10.1073/pnas.172504199

13. Rutten K, Basile JL, Prickaerts J, Blokland A, Vivian JA (2008) Selective PDE inhibitors rolipram and sildenafil improve object retrieval performance in adult cynomolgus macaques. Psychopharmacology 196(4):643-648. https://doi.org/10.1007/s00213-007-0999-1

14. DaSilva JN, Lourenco CM, Meyer JH, Hussey D, Potter W, Houle S (2002) Imaging cAMP-specific phosphodiesterase-4 in human brain with R- $\left[{ }^{11} \mathrm{C}\right]$ rolipram and positron emission tomography. Eur J Nucl Med Mol Imaging 29(12):1680-1683. https://doi.org/10.1007/s00259002-0950-y

15. Parker CA, Matthews JC, Gunn RN, Martarello L, Cunningham VJ, Dommett D, Knibb ST, Bender D, Jakobsen S, Brown J, Gee AD (2005) Behaviour of $\left[{ }^{11} \mathrm{C}\right] \mathrm{R}(-)-$ and $\left[{ }^{11} \mathrm{C}\right] \mathrm{S}(+)$-rolipram in vitro and in vivo, and their use as PET radiotracers for the quantificative assay of PDE4. Synapse 55(4):270-279. https://doi.org/10.1002/syn.20114

16. Fujita M, Zoghbi SS, Crescenzo MS, Hong J, Musachio JL, Lu JQ, Liow JS, Seneca N, Tipre DN, Cropley VL, Imaizumi M, Gee AD, Seidel J, Green MV, Pike VW, Innis RB (2005) Quantification of brain phosphodiesterase 4 in rat with (R)- $\left[{ }^{11} \mathrm{C}\right]$ Rolipram-PET NeuroImage 26(4):1201-1210. https://doi.org/10.1016/ j.neuroimage.2005.03.017

17. Karlsson P, Farde L, Halldin C, Swahn CG, Sedvall G, Foged C, Hansen KT, Skrumsager B (1993) PET examination of $\left[{ }^{11} \mathrm{C}\right] \mathrm{NNC} 687$ and $\left[{ }^{11} \mathrm{C}\right] \mathrm{NNC} 756$ as new radioligands for the D1-dopamine receptor. Psychopharmacology 113(2):149-156. https://doi.org/10.1007/ BF02245691

18. Varrone A, Sjoholm N, Eriksson L et al (2009) Advancement in PET quantification using 3D-OP-OSEM point spread function reconstruction with the HRRT. Eur J Nucl Med Mol Imaging 36(10):16391650. https://doi.org/10.1007/s00259-009-1156-3

19. Zanotti-Fregonara P, Zoghbi SS, Liow JS, Luong E, Boellaard R, Gladding RL, Pike VW, Innis RB, Fujita M (2011) Kinetic analysis in human brain of $\left[{ }^{11} \mathrm{C}\right](\mathrm{R})$-rolipram, a positron emission tomographic radioligand to image phosphodiesterase 4: a retest study and use of an image-derived input function. NeuroImage 54(3):1903-1909. https:// doi.org/10.1016/j.neuroimage.2010.10.064

20. Zanotti-Fregonara P, Liow JS, Fujita M, Dusch E, Zoghbi SS, Luong E, Boellaard R, Pike VW, Comtat C, Innis RB (2011) Image-derived input function for human brain using high resolution PET imaging with $\left[{ }^{11} \mathrm{C}\right](\mathrm{R})$-rolipram and $\left[{ }^{11} \mathrm{C}\right] \mathrm{PBR} 28$. PLoS One 6(2):e17056. https://doi.org/10.1371/journal.pone.0017056

21. Cunningham VJ, Rabiner EA, Slifstein M, Laruelle M, Gunn RN (2010) Measuring drug occupancy in the absence of a reference region: the Lassen plot re-visited. J Cereb Blood Flow Metab 30(1):46-50. https://doi.org/10.1038/jcbfm.2009.190

22. Lassen NA, Bartenstein PA, Lammertsma AA, Prevett MC, Turton DR, Luthra SK, Osman S, Bloomfield PM, Jones T, Patsalos PN, O'Connell MT, Duncan JS, Andersen JV (1995) Benzodiazepine receptor quantification in-vivo in humans using [C-11] flumazenil and pet-application of the steady-state principle. J Cereb Blood Flow Metab 15(1):152-165. https://doi.org/10.1038/jcbfm.1995.17

23. Bethke TD, Bohmer GM, Hermann R et al (2007) Dose-proportional intraindividual single- and repeated-dose pharmacokinetics of roflumilast, an oral, once-daily phosphodiesterase 4 inhibitor. J Clin Pharmacol 47(1):26-36. https://doi.org/10.1177/0091270006294529

24. Hatzelmann A, Morcillo EJ, Lungarella G, Adnot S, Sanjar S, Beume R, Schudt C, Tenor H (2010) The preclinical pharmacology of roflumilast - a selective, oral phosphodiesterase 4 inhibitor in development for chronic obstructive pulmonary disease. Pulm Pharmacol Ther 23(4):235-256. https://doi.org/10.1016/j.pupt.2010.03.011

25. Rabe KF (2011) Update on roflumilast, a phosphodiesterase 4 inhibitor for the treatment of chronic obstructive pulmonary disease. Br J Pharmacol 163(1):53-67. https://doi.org/10.1111/j.14765381.2011.01218.x

26. Zhao Y, Zhang HT, O'Donnell JM (2003) Inhibitor binding to type 4 phosphodiesterase (PDE4) assessed using $\left[{ }^{3} \mathrm{H}\right]$ piclamilast and $\left[{ }^{3} \mathrm{H}\right]$ rolipram. J Pharmacol Exp Ther 305(2):565-572. https://oi.org/ 10.1124/jpet.102.047407

27. Itoh T, Abe K, Zoghbi SS, Inoue O, Hong J, Imaizumi M, Pike VW, Innis RB, Fujita M (2009) PET measurement of the in vivo affinity of $11 \mathrm{C}$-(R)-rolipram and the density of its target, phosphodiesterase-4, in the brains of conscious and anesthetized rats. J Nucl Med 50(5):749756. https://doi.org/10.2967/jnumed.108.058305

28. Bruno O, Romussi A, Spallarossa A, Brullo C, Schenone S, Bondavalli F, Vanthuyne N, Roussel C (2009) New selective phosphodiesterase 4D inhibitors differently acting on long, short, and supershort isoforms. J Med Chem 52(21):6546-6557. https://doi.org/10.1021/jm900977c

29. Oba Y, Lone NA (2013) Efficacy and safety of roflumilast in patients with chronic obstructive pulmonary disease: a systematic review and meta-analysis. Ther Adv Respir Dis 7(1):13-24. https://doi.org/ $10.1177 / 1753465812466167$

30. Hirose R, Manabe H, Nonaka H, Yanagawa K, Akuta K, Sato S, Ohshima E, Ichimura M (2007) Correlation between emetic effect of phosphodiesterase 4 inhibitors and their occupation of the high-affinity rolipram binding site in Suncus murinus brain. Eur J Pharmacol 573(1-3):93-99. https://doi.org/10.1016/j.ejphar.2007.06.045

31. Garnock-Jones KP (2015) Roflumilast: a review in COPD. Drugs 75(14):1645-1656. https://doi.org/10.1007/s40265-015-0463-1

32. Rutter AR, Poffe A, Cavallini P, Davis TG, Schneck J, Negri M, Vicentini E, Montanari D, Arban R, Gray FA, Davies CH, Wren PB (2014) GSK356278, a potent, selective, brain-penetrant phosphodiesterase 4 inhibitor that demonstrates anxiolytic and cognition-enhancing effects without inducing side effects in preclinical species. J Pharmacol Exp Ther 350(1):153-163. https://doi.org/10.1124/jpet.114.214155

33. Vanmierlo T, Creemers P, Akkerman S, van Duinen M, Sambeth A, de Vry J, Uz T, Blokland A, Prickaerts J (2016) The PDE4 inhibitor roflumilast improves memory in rodents at non-emetic doses. Behav Brain Res 303:26-33. https://doi.org/10.1016/j.bbr.2016.01.031

34. Li YF, Cheng YF, Huang Y, Conti M, Wilson SP, O'Donnell JM, Zhang HT (2011) Phosphodiesterase-4D knock-out and RNA interference-mediated knock-down enhance memory and increase hippocampal neurogenesis via increased cAMP signaling. J Neurosci 31(1):172-183. https://doi.org/10.1523/JNEUROSCI.5236-10.2011

35. Bruno O, Fedele E, Prickaerts J, Parker LA, Canepa E, Brullo C, Cavallero A, Gardella E, Balbi A, Domenicotti C, Bollen E, Gijselaers HJM, Vanmierlo T, Erb K, Limebeer CL, Argellati F, Marinari UM, Pronzato MA, Ricciarelli R (2011) GEBR-7b, a novel PDE4D selective inhibitor that improves memory in rodents at non-emetic doses. Br J Pharmacol 164(8):2054-2063. https://doi.org/10.1111/ j.1476-5381.2011.01524.x

36. Titus DJ, Wilson NM, Freund JE, Carballosa MM, Sikah KE, Furones C, Dietrich WD, Gurney ME, Atkins CM (2016) Chronic cognitive dysfunction after traumatic brain injury is improved with a phosphodiesterase 4B inhibitor. J Neurosci 36(27):7095-7108. https://doi.org/ 10.1523/JNEUROSCI.3212-15.2016 